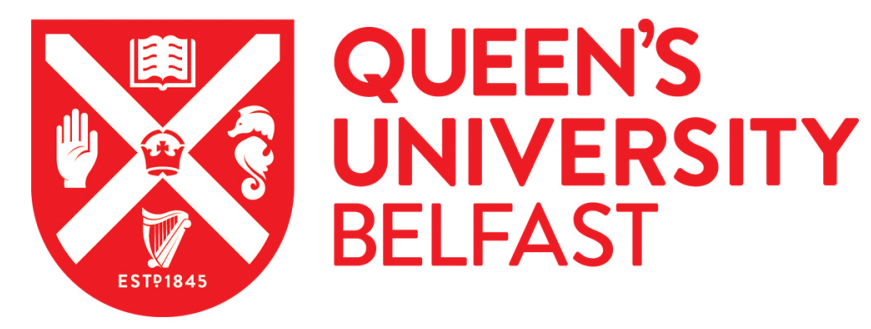

\title{
The value of water quality improvements in the region Berlin- Brandenburg as a function of distance and state residency
}

Meyerhoff, J., Boeri, M., \& Hartje, V. (2014). The value of water quality improvements in the region BerlinBrandenburg as a function of distance and state residency. Water Resources and Economics, 5, 49-66. https://doi.org/10.1016/j.wre.2014.02.001

Published in:

Water Resources and Economics

Document Version:

Peer reviewed version

Queen's University Belfast - Research Portal:

Link to publication record in Queen's University Belfast Research Portal

\section{Publisher rights}

Copyright $\odot 2014$ Elsevier B.V.

This is the author's version of a work that was accepted for publication in Water Resources and Economics. Changes resulting from the publishing process, such as peer review, editing, corrections, structural formatting, and other quality control mechanisms may not be reflected in this document. Changes may have been made to this work since it was submitted for publication. A definitive version was subsequently published in Water Resources and Economics, volume 5, May 2015, doi:10.1016/j.wre.2014.02.001.

\section{General rights}

Copyright for the publications made accessible via the Queen's University Belfast Research Portal is retained by the author(s) and / or other copyright owners and it is a condition of accessing these publications that users recognise and abide by the legal requirements associated with these rights.

\section{Take down policy}

The Research Portal is Queen's institutional repository that provides access to Queen's research output. Every effort has been made to ensure that content in the Research Portal does not infringe any person's rights, or applicable UK laws. If you discover content in the Research Portal that you believe breaches copyright or violates any law, please contact openaccess@qub.ac.uk. 
2 Brandenburg as a function of distance and state residency

3 Abstract: The study uses a discrete choice experiment (DCE) to elicit willingness to pay estimates for 4 changes in the water quality of five river stretches. As many regions the metropolitan region Berlin5 Brandenburg struggles to achieve the objectives of the Water Framework Directive until 2015. A 6 major problem is the high load of nutrients. As the region is part of two states (Länder) and the river 7 sections are common throughout the whole region we account for the spatial context twofold. Firstly, 8 we incorporate the distance between each respondent and all river stretches in all MNL and RPL 9 models, and, secondly, we consider whether respondents reside in the state of Berlin or Brandenburg. The compensating variation (CV) calculated for various scenarios shows that overall people would significantly benefit from improved water quality. The CV measures, however, also reveal that not considering the spatial context would result in severely biased welfare measures. While the distancedecay effect lowers CV state residency is connected to the frequency of status quo choices and not accounting for residency would underestimate possible welfare gains in one state. Another finding is that the extent of the market varies with respect to attributes (river stretches) and attribute levels (water quality levels).

17 Keywords: compensating surplus, distance-decay effect, spatial heterogeneity, spatially explicit choice sets, water quality changes 
The European Water Framework Directive (WFD) has recently moved into a new phase of implementation. Generally, the WFD that entered into force in the year 2000 aims at achieving a good ecological status of all water bodies within the EU. Due to the EU timetable, administrative resources went in the first phases of the WFD implementation mainly to establishing inventories, monitoring networks, and developing first river basin management plans. Currently, i.e. in the phase between 2012 and 2015, administrations are asked to operationalize programmes of measures ensuring that the environmental objectives can be met. It has, however, become obvious that it is very unlikely to reach the above target for all water bodies by 2015 . Thus, management plans and even objectives might have to be adjusted accordingly.

Adjustment will very likely involve balancing costs and benefits of the management actions. It became clear recently that meeting the WFD targets could be costly. This raises the question whether societies are willing to spend the necessary amounts of money to achieve in all water bodies a good ecological status. Although the economic analysis was at the core of the WFD implementation process from the beginning, estimating the benefits associated with a good ecological status was not originally on the agenda. It was latter on suggested by researchers to employ economic valuation when the need to define disproportional high measurement costs became evident (Brouwer [1]; Hanley et al. [2]). Meanwhile, several studies from across Europe determining the benefits of changes in water quality have been presented, e.g., Bliem and Getzner [3]; Brouwer et al. [4]; Glenk et al. [5]; Kataria et al. [6], and Metcalfe et al. [7]. ${ }^{1}$ The studies, using the categorization of water quality levels in the WFD, indicate that people value water quality improvements positively.

Generally, as Schaafsma et al. [36] point out, many valuation studies using stated preference techniques can be characterized as aspatial. A significant finding, however, of some of those studies mentioned above, among others, is that benefits are not evenly distributed spatially. Accounting for the spatial context can thus provide more accurate information for decision makers. The spatial context has been incorporated in the analysis of stated preference data in various forms. The most common is to incorporate the distance between respondents' place of residence and the good in question. The general expectation is that willingness to pay (WTP) estimates decline with the distance between a respondent's place of residence and a policy site. Among others, this effect has been found by Bateman et al. [8], Kataria et al. [6], Schaafsma et al. [36]. Another way to consider the spatial context is to account for the respondents place of residence. For example, Brouwer et al. [4] analysed whether the place of residence in a river basin influences choices among water quality

\footnotetext{
${ }^{1}$ Many of the studies have been conducted as part of the Aquamoney project (http://www.ivm.vu.nl/en/projects/Projects/economics/aquamoney/).
} 
improvement alternatives. Due to spatial heterogeneity, the authors expected respondents to value changes in environmental quality differently depending on where the change takes place. They found that respondents have preferences for acceptable levels of water quality in the entire basin, but have a stronger preference for improvements in their sub basin. The authors argue that aggregating WTP estimates from sub basins to the whole river basin without taking spatial dependence into account would underestimate the welfare effects of improved water quality. Accounting similarly for the spatial context, Tait et al. [9] found that local water quality significantly affected WTP values for a river and stream preservation programme in Canterbury. They also found that not accounting for the spatial sensitivity would result in an underestimation of the welfare gains.

The present study builds on the literature by accounting for the spatial context twofold. Firstly, we incorporate the distance between each respondent and the five river stretches. Interacting the choice attribute levels, the potential water quality improvements, and the distance to a river stretch indicates whether a distance-decay effect is present at all and whether it varies across quality levels. Respondents might, for example, care more about the distance the distance to a certain river when the quality change is only from poor to moderate and might care less when the quality change is to a very good level. Secondly, we account for the spatial distribution of the benefits arising from any water quality improvements. This is done by accounting for whether respondents reside in Berlin (BE) or Brandenburg (BB). Both are separate states (Länder in Germany) with their own governments but constitute both the metropolitan region Berlin-Brandenburg. We define this region as the area of about 80 kilometres around the city centre of Berlin (see Figure 1). The metropolitan region BerlinBrandenburg comprises nearly $90 \%$ of the population of both states together. While BE is a predominantly an urban area, BB, that surrounds Berlin, is within the Berlin hinterland a predominantly suburban area and becomes rural with an increasing distance from Berlin.

The applied discrete choice experiment (DCE) is concerned with the benefits from changing the water quality in the river system in the metropolitan area of Berlin and Brandenburg. The study area is located within the Havel river basin in the East of Germany, itself a sub basin of the Elbe river basin. The Havel basin is one of the five WFD-coordinating areas within the Elbe basin. Major obstacles preventing meeting the WFD objectives for these three rivers are structural and morphological changes in the rivers and high nutrient loads from diffuse sources (agriculture, storm water). The latter leads, among others, again and again to algal blooms during the summer in some of the river stretches. The DCE was designed in an spatially explicit manner, in accordance with choice experiment surveys conducted as part of the Aquamoney project (see footnote 1), as different river stretches are used as attributes. Respondents could therefore choose for which river stretch they prefer what kind of quality improvement. This design allows calculating the compensating variation 
for different scenarios taking into account the quality changes and the location of the river stretches within the study region.

The paper proceeds as follows. In the next section we briefly introduce the DCE method and the econometric analysis used. Section 3 than presents the case study area and the survey design. Subsequently, the estimation results as well as the compensating variation for various quality improvement scenarios are presented before section 5 concludes.

\section{Discrete choice experiments}

Discrete Choice Experiments (CE) is a survey based technique to elicit preferences of citizens on nonmarket goods or services characterized by more attributes. Our study aims at identifying citizens' preferences on different levels of water quality in different stretches of the river system in the metropolitan area of Berlin and Brandenburg.

\section{$2.1 \quad$ The econometric analysis}

In our empirical case we consider the situation in which a subject $n$ has to choose between $J$ alternatives of water improvements in the rivers of the metropolitan region of Berlin and Brandenburg for a sequence of T choice tasks. By assuming that respondents choose by maximizing their utility, we apply a standard random utility model (RUM - see $[10,11])$ in the analysis. Under this setting, the core assumption of CE is that choices are driven by the maximization of respondents' utility. The utility that each alternative brings to the respondents can be represented by the function: $U_{n i t}=\beta^{\prime} X_{n i t}+\varepsilon_{n i t}$

where $n$ indicates the respondent, $i$ the chosen alternative, $t$ the choice occasion, $\mathrm{X}$ is a vector of attributes and other parameters, $\beta$ is a vector of coefficients to be estimated and $\varepsilon$ is a random error term (unobserved by the researcher, often referred to as disturbance) assumed to be iid Gumbel. In the present study the vector of attributes comprises also the distances of each respondent's to each of the five river stretches. The utility function includes an interaction between the levels of the choice attributes, here the river stretches, and the distance to the corresponding river stretch. From the utility function in eq. 1 it is possible to represent the probability for individual $n$ of choosing alternative $i$ over any other alternative $j$ in choice set by a multinomial logit (MNL) model [12] is:

$\operatorname{Pr}_{n^{(i)}}=\frac{e^{V_{i n}}}{\sum_{j=1}^{J} e^{V_{j n}}}$

where $V_{i n}=\beta^{\prime} X_{n i}$. Finally, as we are interested in differences of taste between residents of $B E$ and $B B$, we will estimate two sets of $\beta$ : one for people living in the state of Berlin and one for respondents 
living in the state of Brandenburg. We also interact the alternative specific constant relative to the current situation with some observed characteristics of the respondents.

The MNL assumes independence of irrelevant alternatives (IIA) property which is the same as assuming that everybody in the sample has the same preferences for water quality changes. While in some cases this assumption may hold, a number of empirical studies have shown that there is often heterogeneity in the preferences that individuals hold for different attributes. The limitations of the MNL model in accommodating preference heterogeneity have given rise to a suite of models that fit under the umbrella of mixed logit (MXL) models (McFadden and Train [13]). MXL models can provide a flexible, theoretical and computationally practical econometric method for any discrete choice [13]. The central feature of MXL models is their ability to accommodate random taste variation, unrestricted substitution patterns and correlation in unobserved factors over time (Train [14]). Furthermore, MXL models allow researchers to incorporate in their analysis the correlation between different alternatives by means of error components. MXL models are generally shown to significantly improve model fit $[15,16]$, as well as provide greater insights into choice behaviour [13] and welfare estimation $[17,18,19]$. By applying the MXL model to both sets of betas (for BE and BB) we account for unobserved preference heterogeneity within each group. The model also allows us to incorporate a normal error component structure to nest experimentally designed alternatives [20].

In MXL models, the parameters are allowed to vary across respondents. If the values of the vector of estimated parameters were known with certainty for each respondent, then the probability of respondent n's sequence of choices would be respectively given by:

$$
\operatorname{Pr}\left(y_{n}^{t} \mid \beta_{n}, X_{n}\right)=\prod_{t=1}^{T} \frac{e^{\left(v_{i n t}\right)}}{\sum_{j=1}^{J} e^{\left(V_{j n t}\right)}}
$$

where $y_{n}^{t}$ is the sequence of choices over the T choice occasions for respondent $n$. As it is clearly not possible to know the value of the parameters with certainty for each respondent, random variation is allowed to facilitate the heterogeneity across respondents in estimation. Under this condition, the unconditional choice probability is obtained by integrating the product of logit probabilities over the distribution of $\beta_{\mathrm{n}}$ :

$$
\operatorname{Pr}\left(y_{n}^{t} \mid \beta_{n}, X_{n}\right)=\int \prod_{t=1}^{T} \frac{e^{V_{i n t}}}{\sum_{j=1}^{J} e^{V_{j n t}}} f(\beta) d \beta
$$

We assume normal distributions for the non-monetary attributes but maintain a fixed cost attribute to alleviate problems with taking the ratio of two random parameters [21]. However, the coefficient varies across the two groups of respondents, i.e., inhabitants of $\mathrm{BE}$ or $\mathrm{BB}$. The analyses were 
performed with Biogeme 2.2 [22,23], a new and more flexible version of Biogeme based on python. Models were estimated using the CFSQP algorithm [24] considering the repeated choice nature of the data. Since the choice probabilities in equations 4 has no closed form, it is estimated by maximum simulated likelihood (MSL) with 1000 quasi-random draws via Latin-hypercube sampling [25].

\subsection{Welfare analysis}

Given that one of the main objectives of environmental studies is the assessment of welfare changes, we compute the willingness to pay (WTP) for each attribute taking the ratios between the coefficient estimated for each attribute and the cost coefficient. In the RPL model this can also be done for each individual in the sample conditional to the pattern of choices observed. The conditional marginal WTPs can be computed using the estimator proposed by Greene et al [26]:

$$
\hat{E}\left[W T P_{a t t, n}\right]=\frac{\frac{1}{R} \sum_{r} \frac{-\hat{\beta}_{\text {att }, n}^{r}}{\hat{\beta}_{\text {price, } n}^{r}} L\left(\hat{\beta}_{n}^{r} \mid \mathbf{y}_{n}, \mathbf{x}_{n}\right)}{\frac{1}{R} \sum_{r} L\left(\hat{\beta}_{n}^{r} \mid \mathbf{y}_{n}, \mathbf{x}_{n}\right)}
$$

where $L($.$) is the posterior likelihood of the individual respondents and the \boldsymbol{\beta}_{n}^{r}$ are drawn from the multivariate normal computed at the MSL estimates $\hat{\boldsymbol{\beta}}, \hat{\mathbf{\Omega}}$, and $\mathrm{R}$ the number of pseudo random draws.

Furthermore, given the conditional parameters, we calculate the compensating variation (CV, also referred to as consumer surplus), as described by Hanemann [27], for four specific policy changes of interest in the study. To compute the CV from the MXL model's estimates, it is necessary to obtain the individual-specific posterior estimates (Equation 5, we used $R=100,000$ ) and then compute the difference in log-sum for each individual between the baseline scenario (current situation) and the policy change scenario $[28,29,14]$.

$C V_{n}=-\frac{1}{\beta_{\text {price }}}\left[\ln \sum_{n=1}^{N} V_{1 n}-\ln \sum_{n=1}^{N} V_{0 n}\right]$

where $\mathrm{CV}_{\mathrm{n}}$ is the individual $n$ 's compensating variation for a change from initial conditions $V_{0} n$ (current situation) to the conditions under the program $V_{1} n$ (policy change scenario) and $\beta_{\text {price }}$ is the cost parameter which represents the marginal utility of money. 


\section{Case study area and survey design}

168

169

170

171

172

173

174

175

176

177

178

179

180

181

182

183

184

185

186

187

The three rivers, the Spree, the Dahme, and the Havel, characterise the river system in the metropolitan region of Berlin and Brandenburg. They all are slow-flowing lowland rivers and partly comprise chains of linked lakes, making up the river system within the Havel basin. The river Spree, a left bank tributary of the river Havel, is approximately 400 kilometres long, has its source in the Lusatian Highlands (Lausitzer Bergland) and flows towards the city of Berlin where it merges in Spandau with the river Havel. The Dahme, a tributary of the Spree, is around 95 kilometres in length and expanding in some sections to a chain of lakes. The River Havel itself is a right tributary of the river Elbe with a length of 325 kilometres providing a link in the waterway connections between East and West Germany. Figure 1 shows the locations of the three rivers and indicates the present water quality using the classification system of the WFD. The solid line in the centre of the map indicates the borders of the federal state of Berlin. River stretch c - the City Spree - is completely located within it's borders. Berlin is surrounded by the federal state of Brandenburg.

Water based recreation is a popular activity in the whole region. For example, bathing in the river Spree in Berlin has a long history. At the beginning of the 19th century there were 11 natural outdoor riverside bathing sites within the city. Nowadays it is discussed in Berlin whether swimming in the Spree should be possible again. Moreover, riverside at stretch (a) within the borders of Berlin lies the Strandbad Wannsee, the largest inland lido in Europe. It is strongly visited during the summer months with up to 10000 visitors in one day. Apart from the rivers given in Figure 1 the region has also many lakes. Of the importance of bathing in the lakes and rivers in the metropolitan area of Berlin, for example, see also Meyerhoff et al. [30]. 


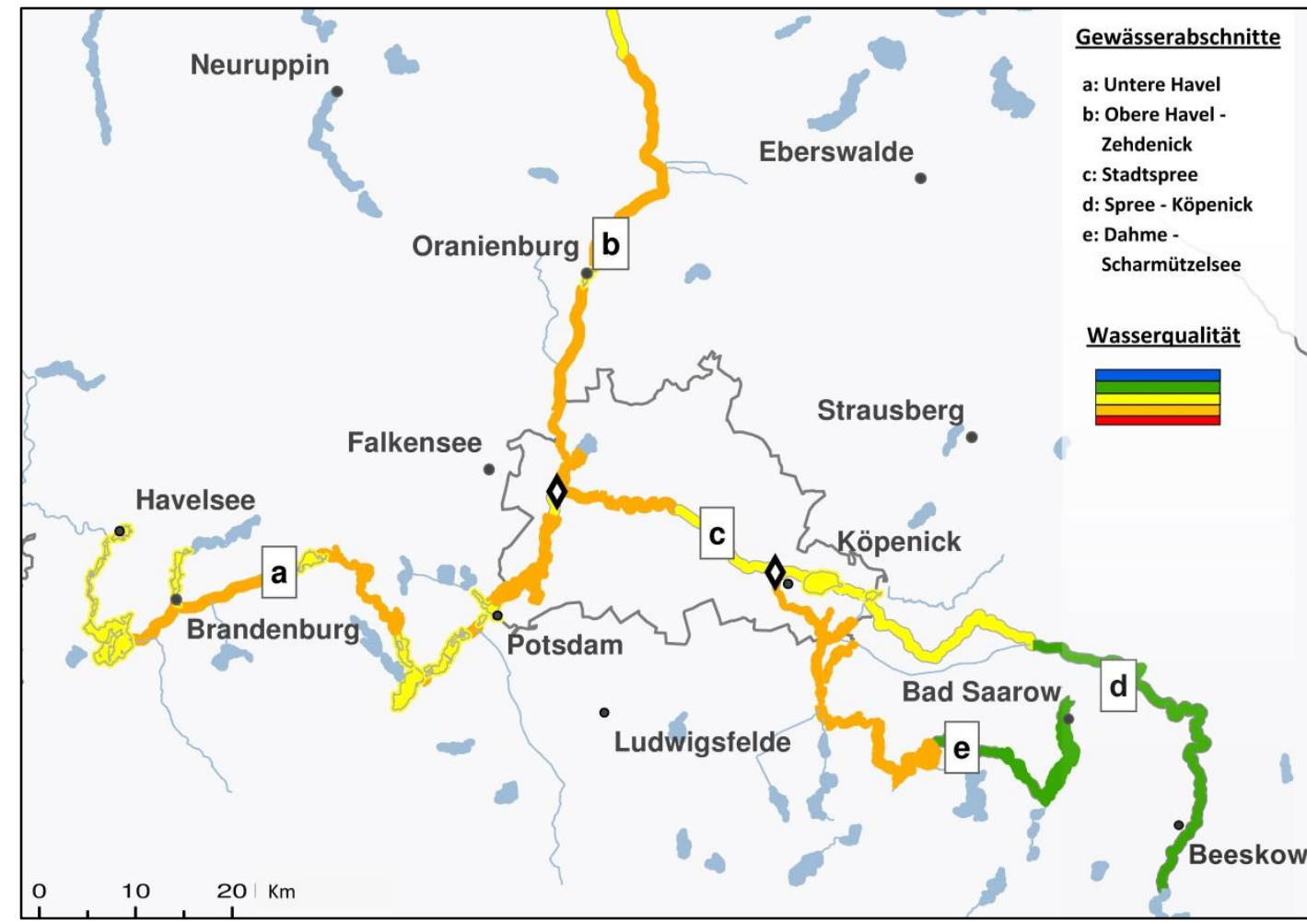

Note: The diamonds mark the end / beginning of a river stretch; the solid line in the centre indicates the border of the federal state of Berlin

Figure 1: Present water quality of river stretches in the region Berlin and Brandenburg

192 In this study the river system was divided into five stretches: the Lower Havel (a), the Upper Havel 193 (b), the city stretch of the Spree (c), the Spree upstream from Koepenick (d), and the Dahme section 194 up to the lake Scharmützelsee (e). The water quality of the stretches is described using a water quality ladder. This ladder ${ }^{2}$, as shown in Figure 2, provides information concerning both the meaning of the different water quality levels for recreational activities as well as for animal and plant species in the region and was developed using the five level classification system of the WFD (BMU [32]). The two lowest categories were merged, as both do not differ significantly with respect to their influence on recreational opportunities or ecological aspects such as species richness. Figure 1 shows the river sections and indicates the present water quality of each river stretch. The diamond each time marks the border between river stretches. The present water quality conditions vary within the stretches. It differs from poor/moderate in the river stretches Lower Havel (a), Upper Havel (b), and the city

\footnotetext{
${ }^{2}$ Originally, it was planned to employ another water quality ladder developed in the Aquamoney project (Hime et al. [31]). It turned out, however, that this ladder is not compatible with information provided by the public administration in Berlin and Brandenburg. The health administration is responsible for informing the public about health risks at bathing sites while the environmental administration is responsible for the environmental quality of the water bodies (e.g., nutrient load). Thus, it could happen that the health administration informs people that no direct health risks exist while at the same time the water quality regarding criteria used in the WFD is rather poor. Linking the water quality and suitability for swimming as it is done on the quality ladder by Hime et al. might thus have been in contrast to peoples' experience in the study region.
} 


\begin{tabular}{|c|c|c|}
\hline Quality levels & Water quality and recreation & $\begin{array}{c}\text { Animal and plant species in and } \\
\text { around the waters }\end{array}$ \\
\hline Very good & $\begin{array}{l}\text { - Very clear water } \\
\text { - Very suitable for swimming and trips } \\
\text { with rowing and paddle boats }\end{array}$ & - Diversity is as in pristine waters \\
\hline Good & $\begin{array}{l}\text { - } \\
\text { - } \\
\text { Suitable for swimming and trips with } \\
\text { rowing and paddle boats }\end{array}$ & $\begin{array}{l}\text { - Diversity differs from pristine waters } \\
\text { - Fish species that demand a high } \\
\text { standard of water quality are rarely } \\
\text { present }\end{array}$ \\
\hline Moderate & $\begin{array}{l}\text { - Slightly turbid water } \\
\text { - In the summer algal blooms can occur } \\
\text { - Limited suitability for swimming, } \\
\text { acceptable for trips with rowing and } \\
\text { paddle boats }\end{array}$ & $\begin{array}{l}\text { Diversity significantly differs from } \\
\text { pristine waters } \\
\text { Because of lack of light less aquatic } \\
\text { plants are present } \\
\text { - There is a risk that there will be fish } \\
\text { kills due to oxygen deficiency }\end{array}$ \\
\hline Poor & $\begin{array}{l}\text { - Turbid water } \\
\text { - In summer large area algal blooms can } \\
\text { occur } \\
\text { - Not suitable for swimming, during trips } \\
\text { with rowing and paddle boats the } \\
\text { recreational value can be limited }\end{array}$ & $\begin{array}{l}\text { - Severely reduced diversity compared to } \\
\text { pristine waters } \\
\text { - Due to the lack of light aquatic plants } \\
\text { are rare } \\
\text { - There is a high risk that there will be } \\
\text { fish kills due to oxygen deficiency }\end{array}$ \\
\hline
\end{tabular}

Figure 2 Water quality ladder

Starting from the present water quality, different improvements are achievable for each river section. Table 1 presents the current water quality according to the EU-WFD classification system for each stretch and reports the potential improvements according to the levels of the water quality ladder. For all stretches except stretch (c) a very good water quality is achievable. Due to its location in the centre of Berlin it is according to the Senate Department for Urban Development and the Environment, Berlin, not possible to reach a very good water quality for this stretch in the foreseeable future. ${ }^{3}$ On the basis of these potential improvements the experimental design was generated. In this design the river sections are the attributes and the potential quality improvements are the levels. Additionally, a cost attribute was added using the same levels as those used by Brouwer et al. [4]. Using a Bayesian D-efficient design (Ferrini and Scarpa [33]), 24 choice sets were created and assigned to two blocks of each time 12 choice sets. The priors used in the design process were derived from choice sets presented at focus groups and a pilot study. In addition to the two hypothetical alternatives (Option 1 and Option 2) each choice set also offered a zero-price alternative without any water quality improvements compared to the current situation (status quo option). An

\footnotetext{
${ }^{3}$ The reasons are, among others, strong obstructions of the banks and non-point source inputs by run-offs from the large sealed surfaces in the city of Berlin.
} 
example of a choice set is presented in Figure $2^{4}$. The attributes and levels were discussed with participants of three focus groups conducted in different locations of the study region.

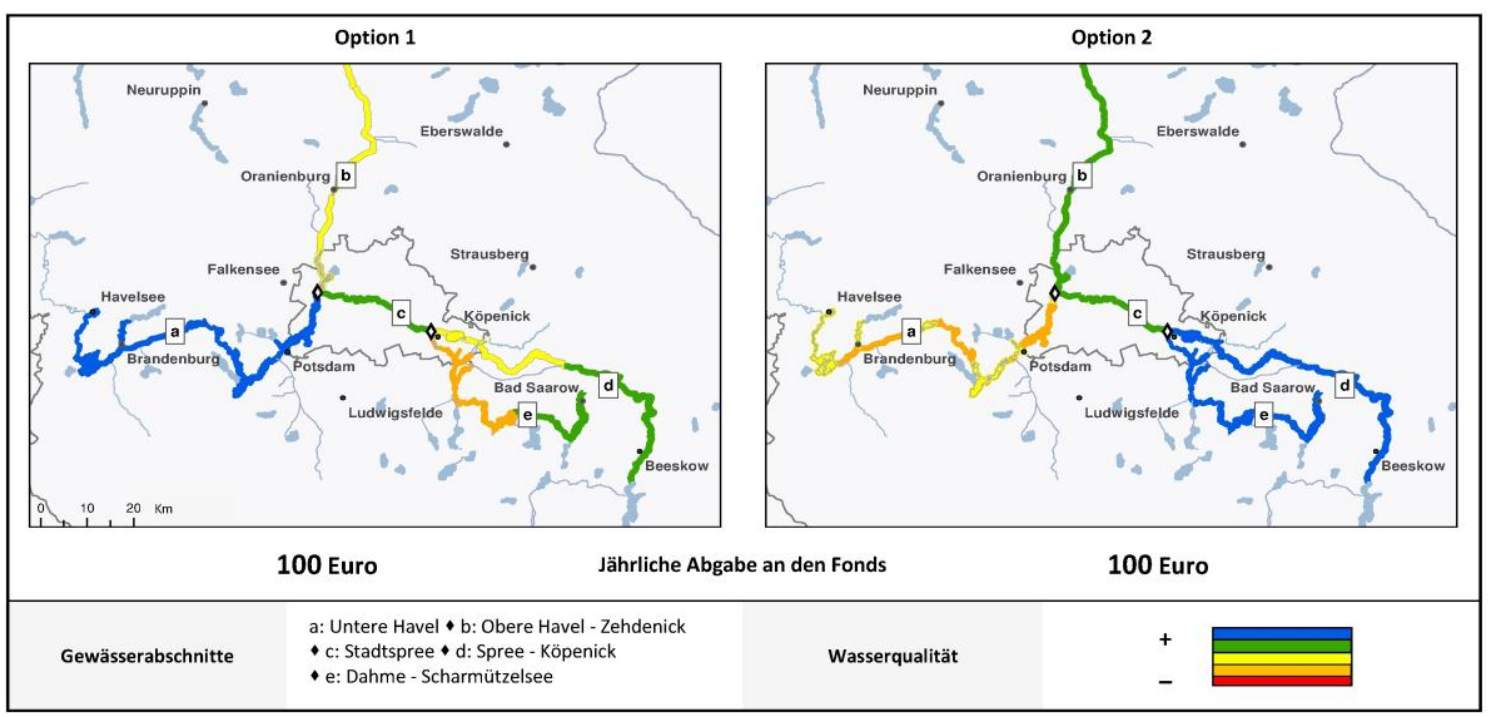

\section{Figure 3 Example choice set}

The survey data were collected in the metropolitan region Berlin-Brandenburg in 2011. For the purpose of this survey, counties at the edge of Brandenburg were not included due to their remoteness to the five river stretches. The survey, conducted by a survey company, proceeded in two-stages. In the first stage a random sample of respondents living in the study region were contacted by phone. If individuals agreed to participate they were interviewed about, for example, their use of water bodies for recreational purposes in the study region and their perception of the water quality. Subsequently attitudinal statements were presented and socio-demographics requested. At the end of the phone interview people were asked whether they are willing to participate in a web-based survey concerned with water quality improvements in the region of Berlin and Brandenburg. Those who agreed were emailed a personalised link to the survey.

\footnotetext{
${ }^{4}$ The radio buttons to choose one of the three options were located on the screen below the choice sets and are thus not visible in Figure 2.
} 


\begin{tabular}{|c|c|c|c|c|c|}
\hline \multicolumn{2}{|l|}{ Attribute } & \multicolumn{4}{|c|}{ Level } \\
\hline & & \multirow{2}{*}{$\begin{array}{l}\text { Present Quality } \\
\text { Poor/moderate }\end{array}$} & \multicolumn{3}{|c|}{ Quality improvements } \\
\hline Stretch a & Lower Havel & & Moderate & Good & $\begin{array}{l}\text { Very } \\
\text { Good }\end{array}$ \\
\hline Stretch b & Upper Havel & Poor/moderate & Moderate & Good & $\begin{array}{l}\text { Very } \\
\text { Good }\end{array}$ \\
\hline Stretch c & $\begin{array}{l}\text { City stretch } \\
\text { Spree }\end{array}$ & Poor/moderate & Moderate & Good &. \\
\hline Stretch d & Spree Köpenick & Moderate/Good &.$/$ & Good & $\begin{array}{l}\text { Very } \\
\text { Good }\end{array}$ \\
\hline Stretch e & $\begin{array}{l}\text { Dahme- } \\
\text { Scharmützelsee }\end{array}$ & Poor/Good & $\begin{array}{l}\text { Moderate / } \\
\text { Good }\end{array}$ & Good & $\begin{array}{l}\text { Very } \\
\text { Good }\end{array}$ \\
\hline \multicolumn{2}{|c|}{$\begin{array}{l}\text { Cost per year in Euro as a } \\
\text { contribution to a fund }\end{array}$} & \multicolumn{4}{|c|}{10 / 25 / 50 / 75 / 100 / 150} \\
\hline
\end{tabular}

The web-based interview proceeded as follows. At the beginning respondents were introduced to the water quality ladder and, using the levels of this ladder, informed about the present water quality of five river stretches (Figure 1). Next, they were informed that it is possible to improve the water quality by, for example, extending sewage treatment plants and by changing agricultural practises. However, as the measure could not be financed completely out of current public budgets, an additional contribution by both private households and businesses would be essential.

242 Respondents were informed that both industry and private households are responsible for the 243 present water quality. Subsequently, the payment vehicle was introduced. The focus groups 244 indicated that a surcharge to the water bill as it was used in other studies $[3,4]$ would very likely increase the number of protest responses. The reason for this is that a very controversial debate within Berlin takes place about whether the main water company, the Berliner Wasserbetriebe, should be run as a private or public company. Currently, it is perceived as a private company but many people are in favour of running it again as a public company. ${ }^{5}$ Many participants of the focus groups indicated that they are willing to pay for improving the current water quality but opposed to pay via a surcharge to their water bill. They were concerned that this would raise the profits of the private company but would not result in a higher water quality of the river and lakes in their region.

252 Thus, as a payment vehicle a contribution to a fund was introduced. Respondents were told that their household would have to pay the stated amount for 10 years from 2012 on and that the fund would be managed by the River Basin Community Elbe. This body is responsible for implementing the

\footnotetext{
${ }^{5}$ Technically, it is a public-law cooperation owned by a private law shareholding cooperation to which two private companies acquired a share of 49.9 per cent in 1999. In 2012, their share went down to 24 per cent.
} 
EU-WFD in the study region. Respondents were also informed that it will take some time before the

256 measures will show effects and that significant improvements could not be expected before 2022. A 257 period of 10 years was chosen because in this period the necessary investments can be made. After introducing the hypothetical market, the choice sets were introduced, and respondents faced the twelve choice sets that were presented to each in a randomized order. The questionnaire concluded with attitudinal questions concerning the choice sets, among others.

\section{4. $\quad$ Results}

\subsection{Descriptive statistics}

Table 2 shows socio-demographics and statistics for the recreational use of rivers and lakes within the region Berlin-Brandenburg. The upper part reports the values for all people who participated in the phone interview while the lower part presents the figures for those who participated in the web-based CE study. Moreover, statistics are presented for inhabitants of BE and BB separately. Overall, 2301 phone interviews and 752 web-based interviews were completed, i.e., these respondents responded to all 12 choice sets. Noteworthy is that the net household income is higher in the area of Brandenburg than in Berlin. Concerning the recreational use of the water bodies in the region, respondents stated that they visited on average 58 times water bodies during the twelve months prior to the interview. The number of visits at water bodies clearly differs. People in the BB made on average around 20 more visits than people from BE. This reflects the larger availability of water bodies for people in the rural area. The major activity at the water bodies is walking while $35 \%$ went swimming and $7 \%$ angling. Accounting for whether a respondent is from the urban or rural area results in significantly different frequencies of recreational activities. 
Table 2: Socio-demographics - population Berlin/Brandenburg, phone sample and subsequent web-survey sample

\begin{tabular}{|c|c|c|c|c|c|c|}
\hline & \multirow[t]{2}{*}{ Berlin Pop } & \multicolumn{2}{|c|}{ Berlin (BE) } & \multirow[t]{2}{*}{ Brandenburg Pop. } & \multicolumn{2}{|c|}{ Brandenburg (BB) } \\
\hline & & mean & $\mathrm{sd}$ & & mean & sd \\
\hline \multicolumn{7}{|l|}{ Phone survey } \\
\hline $\mathrm{N}$ & 3292 (in 1000) & & 1085 & 2495 (in 1000) & & 1096 \\
\hline Age (in years) & 42.3 & 45.27 & 16.47 & 45,8 & 48.30 & 15.60 \\
\hline Gender (1=female) & 0.51 & 0.50 & 0.50 & 0.50 & 0.50 & 0.50 \\
\hline Person per household & 1.7 & 2.07 & 1.11 & 2.0 & 2.31 & 1.11 \\
\hline $\begin{array}{l}\text { Net household income }{ }^{1} \\
\text { (Euro per month) }\end{array}$ & 1650.00 & 2491.05 & 1588.58 & 1750 & 2756.95 & 1596.96 \\
\hline \multicolumn{7}{|l|}{ Education } \\
\hline Realschule (10 years) & 28.7 & 26.1 & & 52.0 & 32.5 & \\
\hline University & 16.8 & 32.7 & & 7.2 & 24.8 & \\
\hline $\begin{array}{l}\text { Number of recreational stays at } \\
\text { water bodies }\end{array}$ & & 46.39 & 67.82 & & 68.71 & 89.93 \\
\hline Swimming (\% of sample) & & 0.33 & 0.47 & & 0.35 & 0.47 \\
\hline Angling (\% of sample) & & 0.05 & 0.22 & & 0.13 & 0.34 \\
\hline \multicolumn{7}{|l|}{ Web-based survey } \\
\hline & & & $N=409$ & & & $N=343$ \\
\hline Age (in years) & 42,3 & 43.66 & 15.18 & 45,8 & 46.44 & 14.70 \\
\hline Gender ( 1 = female) & 0,50 & 0.48 & 0.50 & 0.50 & 0.50 & 0.50 \\
\hline Person per household & 1.7 & 2.08 & 1.12 & 2.0 & 2.44 & 1.23 \\
\hline $\begin{array}{l}\text { Net household income }{ }^{2} \\
\text { (Euro per month) }\end{array}$ & 1650.00 & 2555.95 & 1374.59 & 1750.00 & 3005.83 & 1454.33 \\
\hline \multicolumn{7}{|l|}{ Education } \\
\hline Realschule (10 years school) & 28.7 & 20,8 & & 52,0 & 28,0 & \\
\hline University (\%) & 16,8 & 41,1 & & 7,2 & 31,2 & \\
\hline $\begin{array}{l}\text { Number of recreational stays at } \\
\text { water bodies }\end{array}$ & & 46.62 & 69.58 & & 65.69 & 82.73 \\
\hline Swimming (\% of web-sample) & & 0.31 & 0.46 & & 0.40 & 0.49 \\
\hline Angling (\% of web-sample) & & 0.04 & 0.19 & & 0.11 & 0.31 \\
\hline
\end{tabular}

Note: Due to missing responses 1 ) $n=1681$ observations; 2 ) $n=616$ 
Comparing both the phone and the web-based survey the most obvious difference is with respect to net household income which is on average around $200 €$ higher in the web-based sample. Also the average age is about two years lower while other differences are rather small. Overall, we could not find statistically significant differences between both samples. We therefore conclude that no strong selection bias is present in the data. In contrast, between the subsamples from BE and BB significant differences occur. The household net income is significantly higher in BB. Also the mean age is higher and households do have on average more members. The latter, however, is not statistically significant. Concerning the recreational activities respondents from BB spent more days at water bodies. Also significantly more respondents from the BB subsample have been swimming $(40 \%)$ or angling (11\%) during the twelve months prior to the interview.

At the end of the interview respondents were requested to indicate their place of residence and based on this information we calculated for each respondents the distance, as the crow flies, to each river stretch. Table 3 reports descriptive statistics for respondents' distances to each of the five river stretches. As the figures show, distances vary considerably from a few hundred meters to more than 100 kilometres. The mean distance to all stretches, apart from stretch c, is between 22 and 24 kilometres. However, when we look at respondents in BB, distances can increase to up to 100 kilometres and more for river stretches that are, from their point of view, on the other side of Berlin (last row Table 3). That the distance to stretch $\mathrm{c}$ is on average lower reflects that this stretch is in the centre of the study region, i.e. the centre of Berlin (see Figure 1).

Table 3: Distance of respondents to each river stretch in kilometres

\begin{tabular}{|c|c|c|c|c|c|c|}
\hline & & $\begin{array}{l}\text { Stretch a } \\
\text { (Lower Havel) }\end{array}$ & $\begin{array}{l}\text { Stretch b } \\
\text { (Upper Havel) }\end{array}$ & $\begin{array}{l}\text { Stretch c } \\
\text { (City Spree) }\end{array}$ & $\begin{array}{c}\text { Stretch d } \\
\text { (Spree Köpenick) }\end{array}$ & $\begin{array}{c}\text { Stretch e } \\
\text { (Dahme-Scharm.) }\end{array}$ \\
\hline \multirow[t]{3}{*}{ Mean } & All & 21.64 & 22.53 & 16.44 & 23.57 & 23.82 \\
\hline & $\mathrm{BE}$ & 14.18 & 13.57 & 4.65 & 14.69 & 14.55 \\
\hline & BB & 30.75 & 33.39 & 30.75 & 34.34 & 35.07 \\
\hline \multirow[t]{3}{*}{ Median } & All & 15.48 & 16.56 & 8.96 & 17.60 & 17.91 \\
\hline & $\mathrm{BE}$ & 13.68 & 12.69 & 3.94 & 14.79 & 14.69 \\
\hline & BB & 26.66 & 28.63 & 23.50 & 33.07 & 33.56 \\
\hline \multirow[t]{2}{*}{ Minimum } & $\mathrm{BE}$ & 0.03 & 0.16 & 0.05 & 0.10 & 0.03 \\
\hline & BB & 0.02 & 0.19 & 0.24 & 0.20 & 0.09 \\
\hline \multirow[t]{2}{*}{ Maximum } & BE & 36.04 & 35.69 & 14.31 & 31.00 & 30.89 \\
\hline & BB & 106.72 & 108.66 & 90.41 & 115.16 & 115.06 \\
\hline
\end{tabular}

Note: Due to missing information distance could only be calculated for 737 respondents; $B E=$ Berlin, $\mathrm{BB}=$ Brandenburg.

Table 4 reports the overall number of status quo (zero-price option) choices and the number of respondents who have always chosen the status quo for the total sample and both $\mathrm{BE}$ and $\mathrm{BB}$ 
separately. The overall number of choices is 9036 with $54 \%$ of all choices attributable to respondents from BE. The status quo option was chosen in total 3181 times, slightly more often than one third of all choices (35.2\%). Among inhabitants of BE the status quo was chosen 1480 times (30\%) while among inhabitants of BB it was chosen 1699 times (41\%). However, only 18\% of all respondents have always chosen the status quo option indicating that they are not willing to pay at all. Comparing again $B E$ and $B B$ it turns out that more respondents from $B B$ have always chosen the status quo option.

Table 4: Number of overall status quo choices and always status quo choices (N/\%)

\begin{tabular}{lccc}
\hline & Total & Berlin (BE) & Brandenburg (BB) \\
\hline Observations & $9036(100.0)$ & $4920(100.0)$ & $4116(100.0)$ \\
Status quo choices & $3179(35.2)$ & $1480(30.1)$ & $1699(41.3)$ \\
\hline Respondents & $752(100.0)$ & $409(100.0)$ & $343(100.0)$ \\
Always choosing status quo & $133(17.7)$ & $56(13.7)$ & $77(22.5)$ \\
\hline
\end{tabular}

Note: $\mathrm{n}=9036$ observations and 753 respondents

\subsection{Estimations}

Table 5 presents the parameter estimates from an MNL model with interactions and an RPL model accounting for observed and unobserved heterogeneity. Starting with the MNL model as a benchmark, results indicate that respondents are in favour of higher water quality levels in all river sections. The coefficients for all water quality related attributes are statistically significant with a positive sign except for the change to a moderate quality level for stretches (a), (b) and (c). This disappears in the RPL model. The cost coefficient and the one for the interaction between cost and income have the expected negative (and positive) sign, implying that an option is less likely to be chosen when costs increase and that this is less important for respondents with a higher income (the baseline income for the estimations is EUR 1,700). To avoid losing observations, we set the value of Income equal to zero when there was a missing observation for that variable. By introducing the dummy variable 'N/Alncome' equal to one when there was a missing observation for income and zero otherwise in the model allows us to capture any statistical difference between respondents who reported and those who did not report their income (as suggested in [34]). The positive coefficient for the status quo constant (ASCsq) suggests that overall respondents are reluctant to move away from the current situation, i.e., to give up money for an improved water quality. However, respondents from BE are more likely to move away from the current situation than respondents from BB (ASCsq - Berlin area). BE and BB residents are significantly different also regarding heterogeneity between male and female, swimmers and non-swimmers and anglers and non-anglers. Another form 
of spatial heterogeneity is taken into account interacting the distance between each river stretch and the respondent's residence. We notice that, in general, coefficient estimated for the distances are negative (with some exception probably due to the problematic assumption of preference homogeneity underneath the MNL model): the further respondents live from the river stretch the lower their utility from improving its water quality. The performance of the basic MNL model is rather poor as it assumes that everybody in the sample has the same preferences for water quality changes. This can also cause problems in the estimation of the coefficients associated with some of the parameters of the model. Thus, we move to our second model.

The RPL model accounts for the distance between the respondents' place of residence and each river stretch and whether they reside in the federal state of Berlin or Brandenburg, recognizes unobserved heterogeneity regarding the water quality attributes through normally distributed random parameters as well as unobserved heterogeneity regarding the alternatives through a joint error component of the hypothetical alternatives (Option 1 and Option 2). Finally, the RPL model also considers the panel characteristic of the data due to the 12 choice sets. Compared to the basic MNL model the performance of the RPL model significantly improves. The majority of parameter estimates is again statistically significant with a positive sign indicating preferences for changes of the present water quality. The coefficient for the status quo option ( $\mathrm{ASC}_{\mathrm{sq}}$ ) is highly significant for both respondents living in $\mathrm{BE}$ and in $\mathrm{BB}$, but differs with respect to the sign. Overall respondents would prefer to remain in the current situation instead of giving up money for improved water quality, but on average, inhabitants from BE would experience a negative utility from not moving away from the present situation. As Table 4 shows, the status quo option was chosen more often by inhabitants of BB. However, female respondents, people who were swimming in lakes and rivers or angling during the last twelve months prior to the interview are less in favour of keeping the current situation. The same groups of people are more likely to select the current situation if residing in BE. The common error component among respondents from $\mathrm{BE}$ and $\mathrm{BB}$ is highly significant suggesting that the substitutability between the two hypothetical alternatives, those with improvements over the current situation, and the alternative describing the current situation differs. All coefficients for the distance are negative and mostly significant, indicating as expected that the interest in improving the water quality of a river stretch is negatively correlated to the distance between the river stretches itself and the residence of the respondent. 
Table 5: Results from MNL and RPL models

\begin{tabular}{|c|c|c|c|c|c|c|}
\hline & \multicolumn{2}{|c|}{ MNL } & \multicolumn{4}{|c|}{$\mathbf{R P L}-\mathbf{e c}$} \\
\hline & Par. & s.e. & Par & s.e. & $\mathrm{SD}$ & s.e. \\
\hline Stretch a: moderate & -0.009 & 0.084 & $0.559 *$ & 0.155 & $0.585^{*}$ & 0.125 \\
\hline Stretch a: good & $0.918^{*}$ & 0.073 & $1.937 *$ & 0.123 & 0.119 & 0.247 \\
\hline Stretch a: very good & $1.042 *$ & 0.065 & $2.379 *$ & 0.123 & $0.774 *$ & 0.099 \\
\hline Stretch b: moderate & -0.011 & 0.078 & 0.059 & 0.143 & 0.205 & 0.193 \\
\hline Stretch b: good & $0.811^{*}$ & 0.074 & $1.420 *$ & 0.146 & $0.817 *$ & 0.096 \\
\hline Stretch b: very good & $0.950 *$ & 0.066 & $1.584 *$ & 0.133 & $1.245^{*}$ & 0.089 \\
\hline Stretch c: moderate & $-0.134 *$ & 0.062 & $0.332 *$ & 0.099 & 0.024 & 0.150 \\
\hline Stretch c: good & 0.088 & 0.058 & $0.868 *$ & 0.089 & $0.493 *$ & 0.079 \\
\hline Stretch d: good & $0.377^{*}$ & 0.090 & $0.946^{*}$ & 0.187 & 0.121 & 0.262 \\
\hline Stretch d: very good & $0.785^{*}$ & 0.055 & $1.166^{*}$ & 0.089 & $0.501 *$ & 0.075 \\
\hline Stretch e: moderate & $0.199 *$ & 0.086 & $0.848^{*}$ & 0.183 & $0.397^{*}$ & 0.108 \\
\hline Stretch e: good & $0.589^{*}$ & 0.090 & $1.580 *$ & 0.197 & 0.039 & 0.182 \\
\hline Stretch e: very good & $0.848^{*}$ & 0.066 & $1.409^{*}$ & 0.091 & $0.379 *$ & 0.079 \\
\hline DISTANCE: & & & & & & \\
\hline Stretch a: moderate & 0.0006 & 0.002 & $-0.011^{*}$ & 0.005 & & \\
\hline Stretch a: good & $-0.012 *$ & 0.002 & $-0.028^{*}$ & 0.004 & & \\
\hline Stretch a: very good & $-0.012 *$ & 0.002 & $-0.028 *$ & 0.004 & & \\
\hline Stretch b: moderate & $0.008^{*}$ & 0.002 & 0.002 & 0.005 & & \\
\hline Stretch b: good & -0.003 & 0.002 & $-0.015^{*}$ & 0.005 & & \\
\hline Stretch b: very good & -0.003 & 0.002 & $-0.009 *$ & 0.004 & & \\
\hline Stretch c: moderate & $0.005^{*}$ & 0.002 & -0.003 & 0.004 & & \\
\hline Stretch c: good & 0.003 & 0.002 & -0.007 & 0.004 & & \\
\hline Stretch d: good & 0.003 & 0.003 & -0.010 & 0.006 & & \\
\hline Stretch d: very good & $-0.009 *$ & 0.001 & $-0.015^{*}$ & 0.003 & & \\
\hline Stretch e: moderate & $0.005^{*}$ & 0.002 & -0.002 & 0.006 & & \\
\hline Stretch e: good & -0.003 & 0.002 & $-0.014 *$ & 0.006 & & \\
\hline Stretch e: very good & $-0.008 *$ & 0.002 & $-0.015^{*}$ & 0.003 & & \\
\hline ASCsq & $1.723^{*}$ & 0.107 & $1.000^{*}$ & 0.474 & & \\
\hline Interactions: & & & & & & \\
\hline $\mathrm{ASCsq} * \mathrm{BE}$ area & $-1.027 *$ & 0.085 & $-2.516^{*}$ & 0.563 & & \\
\hline Female * BB area & $-0.271 *$ & 0.067 & $-1.418^{*}$ & 0.499 & & \\
\hline Female $*$ BE area & $0.589^{*}$ & 0.093 & $1.716^{*}$ & 0.653 & & \\
\hline Swim * BB area & $-0.261^{*}$ & 0.068 & $-1.441 *$ & 0.466 & & \\
\hline Swim * BE area & $0.591 *$ & 0.097 & $2.454^{*}$ & 0.643 & & \\
\hline Anglers * BB area & $-0.514 *$ & 0.111 & -1.240 & 0.850 & & \\
\hline Anglers * BE area & $0.955^{*}$ & 0.196 & $3.844^{*}$ & 1.624 & & \\
\hline Cost & $-0.009 *$ & 0.0007 & $-0.035^{*}$ & 0.0012 & & \\
\hline Cost $*$ Income $/ 1000$ & $0.002 *$ & 0.0002 & $0.002^{*}$ & 0.0004 & & \\
\hline Cost $*$ N/A Income & $-0.002 *$ & 0.0007 & 0.001 & 0.0019 & & \\
\hline $\begin{array}{l}\text { Error Component } \\
\text { (common urban-rural) }\end{array}$ & & & & & $6.274^{*}$ & 0.280 \\
\hline $\log L$ & $-8,80$ & 782 & & $-5,63$ & 807 & \\
\hline $\mathrm{K}$ & 3 & & & & & \\
\hline $\mathrm{AIC} / \mathrm{N}$ & 1.5 & & & & & \\
\hline Observations & 90 & & & & & \\
\hline Respondents & & & & & & \\
\hline
\end{tabular}

* Significant at least at 5\% level; all water quality attributes were specified as following a normal distribution 


\subsection{Welfare analysis}

Our welfare analysis is performed on the RPL model (see Section 2.2). Table 6 reports the mean WTP estimates and the $95 \%$ confidence intervals for each river stretch and each quality level as well as the mean of individual conditional posterior estimates separately for the states BE and BB. The Table also reports the change in WTP with an increasing distance to each of the river stretches. Generally, quality changes to a higher level of water quality result in larger WTP estimates. The only exception is for stretch $\mathrm{d}$. Here the mean value for a change from the present situation to a very good water quality, the highest level, is lower than the mean value for an improvement to a good quality level. Moreover, respondents do not seem to value changes to a moderate quality level as a significant improvement for stretch $b$.

The changes in WTP due to an increasing distance from the river stretches are reported in the lower part of Table 6. They are significant for quality improvements to "good" or "very good" quality levels. Only for stretch c, which is the City Spree located in the center of Berlin, we could not find a significant distance decay. Why this is the case is not clear from the data. We can only speculate why WTP does not decrease with distance. This part of the Spree is to some extent a land mark as it flows through the historical part of Berlin and the government district and is well known to people and many visitors take the famous boat trip on this stretch through the center of Berlin. Thus, people might feel a special attachment to this river stretch.

Next, it is noteworthy that the distance-decay effect varies across river stretches and quality levels. The strongest effect occurs for the quality levels "good" and "very good" for the Lower Havel stretch. Here an increase in the distance by one kilometer corresponds to a WTP decrease of $€ 0.80$. The lowest decrease, on the other hand, is connected to the Upper Havel and a quality change to "very good" for this stretch. One more kilometer distance leads for this stretch and a "very good" quality to a WTP decrease of $€ 0.26$. As not only the distance-decay effect varies but also the mean WTP estimates are varying we get different values for the geographical boundaries of the market for quality improvements (Extent of the market, also reported in the lower part of Table 6). Distances range for the statistically significant effects from 52 kilometers for only a modest improvement in the Lower Havel to 174 kilometers for an improvement to a "very good" quality in the Upper Havel. Thus, higher quality improvements seem to travel further. This is an important finding for decision makers as the decision to improve the water quality to a higher level would affect more people positively. 
Table 6: WTP (€/year) from RPL model.

\begin{tabular}{|c|c|c|c|c|c|c|}
\hline \multirow{2}{*}{$\begin{array}{l}\text { Attribute - water quality } \\
\text { improvement } \\
\text { Stretch a: poor/moderate -> moderate }\end{array}$} & \multirow{2}{*}{$\begin{array}{l}\text { WTP } \\
16.01^{*}\end{array}$} & \multirow{2}{*}{$\begin{array}{l}\text { s.e. } \\
4.51\end{array}$} & \multicolumn{2}{|c|}{$\begin{array}{c}95 \% \\
\text { Confidence } \\
\text { Interval }\end{array}$} & \multirow{2}{*}{$\begin{array}{c}\begin{array}{c}\mathrm{BE} \\
\text { mean WTP }\end{array} \\
17.10\end{array}$} & \multirow{2}{*}{$\begin{array}{c}\begin{array}{c}\text { BR mean } \\
\text { WTP }\end{array} \\
17.31\end{array}$} \\
\hline & & & 7.16 & 24.85 & & \\
\hline Stretch a: poor/moderate -> good & $55.46^{*}$ & 4.04 & 47.55 & 63.38 & 56.16 & 56.17 \\
\hline Stretch a: poor/moderate -> very good & $68.10^{*}$ & 3.76 & 60.73 & 75.48 & 67.87 & 68.90 \\
\hline Stretch b: poor/moderate -> moderate & 1.70 & 4.11 & -6.35 & 9.75 & 1.69 & 1.65 \\
\hline Stretch b: poor/moderate -> good & $40.64 *$ & 4.49 & 31.84 & 49.45 & 39.44 & 41.74 \\
\hline Stretch b: poor/moderate -> very good & $45.34 *$ & 3.82 & 37.85 & 52.83 & 43.62 & 47.84 \\
\hline Stretch c: poor/moderate -> moderate & $9.50^{*}$ & 2.85 & 3.92 & 15.08 & 9.48 & 9.49 \\
\hline Stretch c: poor/moderate -> good & $24.83 *$ & 2.45 & 20.03 & 29.64 & 25.44 & 24.76 \\
\hline Stretch d: moderate/good -> good & $27.09 *$ & 5.17 & 16.97 & 37.22 & 27.14 & 27.16 \\
\hline Stretch d: moderate/good -> very good & $33.37^{*}$ & 2.69 & 28.10 & 38.64 & 33.34 & 33.77 \\
\hline Stretch e: poor/good -> moderate & $24.28 *$ & 5.17 & 14.16 & 34.41 & 24.71 & 24.06 \\
\hline Stretch e: poor/good -> good & $45.22 *$ & 5.41 & 34.60 & 55.83 & 45.21 & 45.23 \\
\hline Stretch e: poor/good -> very good & $40.33^{*}$ & 2.97 & 34.50 & 46.16 & 39.87 & 40.46 \\
\hline \multicolumn{5}{|c|}{ DISTANCE - change in WTP increasing distance $(1 \mathrm{Km}$.$) from the stretch:$} & \multicolumn{2}{|c|}{ Extend of the market } \\
\hline Stretch a: poor/moderate -> moderate & $-0.31^{*}$ & 0.14 & -0.59 & -0.02 & $52 \mathrm{~km}$ & \\
\hline Stretch a: poor/moderate -> good & $-0.80^{*}$ & 0.12 & -1.04 & -0.56 & $69 \mathrm{~km}$ & \\
\hline Stretch a: poor/moderate -> very good & $-0.80^{*}$ & 0.13 & -1.05 & -0.55 & $85 \mathrm{~km}$ & \\
\hline Stretch b: poor/moderate -> moderate & 0.05 & 0.13 & -0.20 & 0.30 & & \\
\hline Stretch b: poor/moderate -> good & $-0.42 *$ & 0.14 & -0.69 & -0.15 & $96 \mathrm{~km}$ & \\
\hline Stretch b: poor/moderate -> very good & $-0.26 *$ & 0.12 & -0.50 & -0.01 & $174 \mathrm{~km}$ & \\
\hline Stretch c: poor/moderate -> moderate & -0.09 & 0.11 & -0.31 & 0.12 & & \\
\hline Stretch c: poor/moderate -> good & -0.19 & 0.12 & -0.44 & 0.05 & & \\
\hline Stretch d: moderate/good -> good & -0.27 & 0.17 & -0.61 & 0.07 & & \\
\hline Stretch d: moderate/good -> very good & $-0.43^{*}$ & 0.09 & -0.61 & -0.25 & $77 \mathrm{~km}$ & \\
\hline Stretch e: poor/good -> moderate & -0.07 & 0.18 & -0.41 & 0.28 & & \\
\hline Stretch e: poor/good -> good & $-0.40^{*}$ & 0.19 & -0.77 & -0.04 & $113 \mathrm{~km}$ & \\
\hline Stretch e: poor/good -> very good & $-0.43^{*}$ & 0.09 & -0.62 & -0.25 & $76 \mathrm{~km}$ & \\
\hline
\end{tabular}

* Significant at least at $5 \%$ level

Based on the previous results, we compute the compensating variation for four scenarios as identified in Table 7. The first scenario "Simply the best" has the quality levels always at the highest possible level. Thus, all quality levels range at "very good" except for the river section (c) for which the quality cannot be improved beyond a good status. The second scenario reflects the objective of the EU-WFD that aims at achieving a good status for all water bodies. The remaining two scenarios each time change the quality of two river stretches to a good water quality and leave all remaining 
stretches unchanged. The difference is that in Scenario 3 both stretches are located west of Berlin (stretch a and b) while in Scenario 4 they are located east of Berlin (stretch $d$ and e).

Table 7: Scenarios for calculating compensating variation measures

\begin{tabular}{lcccc}
\hline Section in Map & $\begin{array}{c}\text { Scenario 1: } \\
\text { Simply the best }\end{array}$ & $\begin{array}{c}\text { Scenario 2: } \\
\text { EU-WFD }\end{array}$ & $\begin{array}{c}\text { Scenario 3: } \\
\text { west of Berlin }\end{array}$ & $\begin{array}{c}\text { Scenario 4: } \\
\text { east of Berlin }\end{array}$ \\
\hline Stretch a & Very good & Good & Good & No change \\
Stretch b & Very good & Good & Good & No change \\
Stretch c & Good & Good & No change & No change \\
Stretch d & Very good & Good & No change & Good \\
Stretch e & Very good & Good & No change & Good \\
\hline
\end{tabular}

The mean and median CV for all four scenarios are reported in Table 8. Implementing the EU-WFD scenario would result in a mean CV of $€ 181$ per year for respondents from BE and $€ 72$ for respondents from $\mathrm{BB}$, less than half the value for inhabitants of Berlin. The value of implementing the scenario would be $€ 131$ per year if computed from the overall sample. Inhabitants of both BE and $\mathrm{BB}$ would experience additional welfare gains of less than $€ 20$ per year when a very good quality would be achieved (Scenario "simply the best"). Table 8 reports as well the CV estimates when we do not consider distance in the CV calculations, i.e. these figures are based on a model without incorporating distance. ${ }^{6}$ In this case the CV estimate strongly increases. For the EU-WFD scenario the mean value would be $€ 179$ per year. This is close to $€ 50$ more per year compared to taking distance to the river stretches into account.

Looking at the two remaining scenarios 'west of Berlin' and 'east of Berlin' reveals that improving the two stretches in the west would result in higher welfare gains. This reflects that current quality levels are lower in this area and gains are thus valued more positively. The finding signals validity of the stated WTP values as smaller changes in water quality also result in lower WTP values. In both cases, however, the improvement would not be beneficial (negative CV) for inhabitants of BB; this is due to the distance-decay effect. As these stretches are for some respondents in BB on the other side of Berlin the distance could be more than 100 kilometers (Table 3). This distance is for the stretches a and $\mathrm{b}$ already beyond the market extend (Table 6). How strongly the distance-decay influences the CV measures can again be seen here. When we do not account for distance the CV would also for the two scenarios 3 (west of Berlin) and 4 (east of Berlin) be distinctly positive with a difference of $€ 100$

\footnotetext{
${ }^{6}$ This model is not reported in the present paper due to limit space but is available from the authors upon request.
} 
per person per year. It is obvious that any recommendation to decision makers based on CV measures without distance would be misleading as it assumes that people far away form the policy site would strongly benefit from water quality changes.

Overall, the $\mathrm{CV}$ of respondents from $\mathrm{BE}$ is higher in all scenarios than the $\mathrm{CV}$ of inhabitants of $\mathrm{BB}$. People living in Berlin would accordingly benefit more from the water quality improvements defined in the four scenarios. The reason for this is mainly the opposite sign of the coefficients of the ASC for the current situation. Inhabitants from BE are in favor of moving away from the current situation while those from BB are on average not in favor of such a move. Taking state residency into account allows thus a better adaptation and is meaningful when it comes to aggregation as the number of dwellers in both states differs. The WTP values for the water quality changes, on the other hand, generally do not differ much between dwellers from BE and BB (see Table 6).

Table 8: Mean and median compensating variation in $€$ per year for the improvement scenarios

\begin{tabular}{|c|c|c|c|c|c|c|c|c|}
\hline \multirow[b]{2}{*}{ Distance considered } & \multicolumn{2}{|c|}{$\begin{array}{l}\text { Scenario 1: } \\
\text { Simply the best }\end{array}$} & \multicolumn{2}{|c|}{$\begin{array}{l}\text { Scenario 2: } \\
\text { EU-WFD }\end{array}$} & \multicolumn{2}{|c|}{$\begin{array}{c}\text { Scenario 3: } \\
\text { west of Berlin }\end{array}$} & \multicolumn{2}{|c|}{$\begin{array}{l}\text { Scenario 4: } \\
\text { east of Berlin }\end{array}$} \\
\hline & Yes & No & Yes & No & Yes & No & Yes & No \\
\hline overall Mean & 149 & 197 & 131 & 179 & 39 & 105 & 16 & 91 \\
\hline overall Median & 163 & 194 & 153 & 179 & 62 & 107 & 46 & 94 \\
\hline BE Mean & 198 & 212 & 181 & 195 & 87 & 121 & 66 & 107 \\
\hline BE Median & 201 & 214 & 183 & 199 & 90 & 125 & 70 & 112 \\
\hline BB Mean & 92 & 178 & 72 & 159 & -19 & 87 & -42 & 73 \\
\hline BB Median & 90 & 168 & 73 & 148 & -17 & 77 & -40 & 63 \\
\hline
\end{tabular}

Finally, Table 9 reports aggregated figures for the EU-WFD improvement scenario. This scenario is chosen because it is the most policy relevant regarding the EU-WFD objective. The CV is aggregated for both respondents from $\mathrm{BE}$ and $\mathrm{BB}$ separately. The number of households was calculated by dividing the number of inhabitants, identified through GIS data provided by the Statistical Office for Berlin-Brandenburg [33], by the average number of persons per household in BE (mean 1.7) and in BB (mean 2.0). Overall, achieving a good water quality as intended by the EU-WFD would result in benefits of Mio $€ 419$ per year if we sum the aggregated mean values for BE and BB. As BB is less populated and respondents from this region would experience lower welfare gains from water quality changes, more than four-fifths of the total welfare gain would come from the population of Berlin.

To demonstrate how strongly the distance-decay effect impacts on CV measures we again present figures for the EU-WFD improvement scenario based on models with and without distance considered. The results demonstrate, particularly for $\mathrm{BB}$, to what extent welfare gains would be 
overestimated. The figures for BB would double reflecting the huge impact distances have in a territorial state such as Brandenburg. For BE, on the other hand, differences would not be as big but are still in the range of Mio $€ 30$. The last column in Table 9 reports CV measures calculated directly from the model (Table 5) without considering state residency. The figures presented in the previous columns base on the conditional parameters. For the estimates calculated based on model parameters we find a lower mean CV value. Thus, not considering state residency might underestimate the total welfare gain. However, when we look at the median this reverses.Table 9: Aggregated yearly compensating variation metropolitan region Berlin-Brandenburg

\begin{tabular}{|c|c|c|c|c|}
\hline & \multirow[b]{2}{*}{$\begin{array}{c}\text { Berlin } \\
(\mathrm{BE})\end{array}$} & \multicolumn{3}{|c|}{ Scenario EU-WFD in $€ /$ year } \\
\hline & & $\begin{array}{c}\text { Brandenburg } \\
(\text { BB })\end{array}$ & $\mathbf{B E}+\mathbf{B B}$ & Overall sample \\
\hline Households & 1958128 & 907970 & 2866098 & 2866098 \\
\hline \multicolumn{5}{|l|}{ Distance considered } \\
\hline $\begin{array}{l}\text { Aggregated value } \\
\text { based on mean CV }\end{array}$ & 354627164 & 65299109 & 419926273 & 376101003 \\
\hline $\begin{array}{l}\text { Aggregated value } \\
\text { based on median CV }\end{array}$ & 359257002 & 66581271 & 425838273 & 437186491 \\
\hline \multicolumn{5}{|l|}{ Distance not considered } \\
\hline $\begin{array}{l}\text { Aggregated value } \\
\text { based on mean CV }\end{array}$ & 382521015 & 144342971 & 526863987 & 512263091 \\
\hline $\begin{array}{l}\text { Aggregated value } \\
\text { based on median CV }\end{array}$ & 389050619 & 134518797 & 523569416 & 514327771 \\
\hline
\end{tabular}

Note: The values for BE and BB base on conditional parameters, those for the overall sample are calculated directly using the model parameters (Table 6) without considering state residency (BE vs BB)

\section{Discussion and conclusions}

The present study reports results from the first survey in Germany eliciting the benefits people would derive from achieving the EU-WFD objective. The results indicate that in the closer metropolitan area Berlin-Brandenburg people value changes in water quality positively. Results are therefore in line with studies from other countries (see $[3,4,5,6,7])$. The mean compensating variation measure for the metropolitan area results in an aggregated overall measure of around Mio $€ 420$ per year for a good water quality in accordance with the EU-WFD objectives. Moreover, our analysis clearly shows that taking into account the spatial context is crucial for aggregating welfare measures. We have accounted for the spatial context in our analysis on two levels. Firstly, we have incorporated the distance of each respondent to all five river stretches. Based on information respondents provided about their place of residence we calculated in a GIS the nearest distance to each river stretch. 
Secondly, we additionally recognized whether respondents reside in the state of Berlin (BE) or Brandenburg (BB). While the state of $\mathrm{BE}$ could be characterized as rather urban, the state $\mathrm{BB}$ is within the Berlin hinterland a predominantly suburban area and becomes more and more rural with an increasing distance to Berlin. Not surprisingly, a significant difference between both states is that BB has much more lakes and rivers and offers inhabitants more opportunities for water based recreation and thus more substitute sites for the river sections valued in this paper.

The model results show that both approaches to account for the spatial context significantly impact model results. Respondents do indeed value improvements less the more remote they live from a river stretch, and for state residency we found opposite signs of the ASC for the status quo option. This strongly influences $\mathrm{CV}$ measures. $\mathrm{CV}$ values for $\mathrm{BE}$ and $\mathrm{BB}$ are much larger if we do not account for the distance-decay effect. Looking at the CV measures for BB, figures more than double when one does not account for distance. This becomes even more evident when we calculate the $\mathrm{CV}$ for quality changes only in the west or the east of Berlin. In this case the distance to the corresponding river stretches becomes for some of the respondents more than 100 kilometers. Assuming that distance does not matter for those respondents would clearly overestimate the welfare effects from increasing the water quality in river stretches that are far away.

The model estimates show that differences between the two federal states is particularly driven by the different signs and sizes of the ASC parameter capturing the status quo. Respondents from BE are, on average, in favor of moving away from the present situation. For respondents from BB the results suggest the opposite. A reason for this might be that inhabitants of BB have more substitute sites such as lakes available in their surroundings and therefore have less strong preferences for changing the current water quality of the river stretches. Alternatively, it is discussed in the literature whether such a finding is the consequence of a status quo bias, i.e., that respondents have an unduly propensity to choose the status quo option (Lanz and Provinz [34]; Meyerhoff and Liebe [35]). While not determining the motives for choosing the status quo option here, we assume that with 82 percent of the respondents at least once choosing an option with an improved water quality and a positive price the survey is not impaired by a status quo bias. Rather, we interpret the choices of the SQ option as preference driven because there is no obvious reason why people in BB should be more prone to a status quo bias, especially when we recognise that on average net household income is higher and more water bodies as potential substitutes to the river stretches are available in BB.

Whether the estimated benefits will outweigh the costs of achieving the EU-WFD objectives is an open question. Currently the costs of implementing the measures needed to reach EU-WFD objectives in the study region are calculated using the MONERIS nutrient emission model (http://moneris.igb-berlin.de). The model enables quantifying the management measures needed 
within the river catchment, e.g., changes of agricultural practices, construction of drain ponds, extending current wastewater treatment plants or building additional ones. Once the costs are determined detailed cost benefit comparisons will be conducted. However, a rough cost figure provided by the Federal Ministry of the Environment [29] already sheds some light on the cost benefit ratio. The ministry estimates that the measures required for the whole of Germany would cost 9.4 billion or approximately 20 Euros per capita and year for 2010 to 2015 . Taking into account that the average household in the study region has less than 2.5 members, costs per household would be around $€ 50$ per year for a five year period. Thus, with a median CV larger than than $€ 70$ per year for inhabitants of BB even when we consider distance the benefits would clearly outweigh the costs. Moreover, the Federal Ministry assumes a five year period, in the survey people were asked for a ten year period of payments. Achieving a good water quality in the metropolitan region BerlinBrandenburg is therefore likely to result in significant welfare gains. Taking into account that in other regions in Germany people have on average rather higher incomes, our estimates base on an average income of $€ 1700$ per household, the findings also suggest that achieving a good status for all rivers and lakes in Germany are likely to be advantageous from an economic point of view. Detailed cost calculations are nonetheless essential.

Overall, our results clearly support findings from other studies on the need to account for the spatial context (see $[4,6,8,9,38]$ ). Not considering for the distance-decay effect could especially in a territorial state such as Brandenburg lead to severely overestimating welfare gains. State residency, as it was considered here, may reflect in the present case differences in the endowment with lakes and rivers. Respondents in $\mathrm{BB}$ have more often opted for the SQ option although average net household income is higher. We therefore think that this is a result of having more substitutes available. Accounting for the spatial characteristics, however, could be further refined. From the first part of our survey, the phone survey recording recreational activities, we know whether people visited more frequently lakes or river stretches for recreational purposes during the twelve months prior to the interview. Incorporating this information could show whether people who prefer lakes for swimming, for example, have a lower willingness to pay for the quality improvements of the river stretches. Moreover, as we also have information about water bodies people have visited this could be used to determine the distance and direction of the lakes or river stretch visited. Considering potential substitute sites might help to shed further light, as suggested by Schaafsma et al. [8], on the shape of the distance-decay effect and to what extent it varies across sites, respondents, directions, and with the availability of substitute sites. 


\section{References}

[1] R. Brouwer, The potential role of stated preference methods in the Water Framework Directive to assess disproportionate costs. J Environ Plann Man 51 (2008) 597-614.

[2] N. Hanley, R.E. Wright, B. Alvarez-Farizo, Estimating the Economic Value of Improvements in River Ecology Using Choice Experiments: An Application to the Water Framework Directive, Journal of Environmental Management 78 (2006) 183-193.

[3] M. Bliem, M. Getzner, Willingness-to-pay for river restoration: differences across time and scenarios, Environmental Economics and Policy Studies 14 (2012) 241-260

[4] R. Brouwer, J. Martin-Ortega, J. Berbel, Spatial Preference Heterogeneity: A Choice Experiment, Land Economics 86 (2010) 552-568.

[5] K. Glenk, M. Lago, D. Moran, Public preferences for water quality improvements: implications for the implementation of the EC Water Framework Directive in Scotland. Water Policy 13 (2011) 645662.

[6] M. Kataria, I. Bateman, T. Christensen, A. Dubgaard, B. Hasler, S. Hime, J. Ladenburg, G. Levin, L. Martinsen, C. Nissen, Scenario realism and welfare estimates in choice experiments - A non-market valuation study on the European water framework directive. J Environ Manage 94 (2012) 25-33.

[7] P. Metcalfe, P. W. Baker, K. Andrews, G. Atkinson, I. J. Bateman, S. Butler, R. T. Carson, J. East, Y. Guéron, R. Sheldon, K. Train, An assessment of the nonmarket benefits of the Water Framework Directive for households in England and Wales, Water Resources Ressearch, (2012) in press

[8] I. J. Bateman, R. Brouwer, S. Ferrini, M. Schaafsma, D. N. Barton, A. Dubgaard, B. Hasler,S. Hime, I. Liekens, S. Navrud, L. De Nocker, R. Ščeponavičiūtè, D. Semènienè, Making Benefit Transfers Work: Deriving and Testing Principles for Value Transfers for Similar and Dissimilar Sites Using a Case Study of the Non-Market Benefits of Water Quality Improvements Across Europe. Environmental and Resource Economics 50 (2011) 365-387.

[9] P. Tait, R. Baskaran, R. Cullen, K. Bicknell, Nonmarket valuation of water quality: Addressing spatially heterogeneous preferences using GIS and a random parameter logit model, Ecological Economics 75 (2012) 15-21.

[10] L. Thurstone, A law of comparative judgment, Psychological Review 34 (1927) 273-286.

[11] C. F. Manski, Structure of Random Utility Models, Theory and Decision 8 (1977) 229-254.

[12] D. L. McFadden, Conditional logit analysis of qualitative choice behavior, Frontiers in econometrics, New York (1974) Academic Press.

[13] D. McFadden, K. Train, Mixed MNL models for discrete response, Journal of Applied Econometrics 15 (2000) 447-470.

[14] K. E. Train, Discrete Choice Methods with Simulation. Cambridge 2003.

[15] D. A. Hensher, W. H. Greene, The Mixed Logit model: The State of Practice, Transportation 30 (2003) 133-176.

[16] D. Rigby, K. Balcombe, M. Burton, Mixed logit model performance and distributional assumptions: preferences and GM foods, Environmental and Resource Economics 42 (2009) 279-295.

[17] M. Sillano, J. D. Ortúzar, Willingness-to-pay estimation with mixed logit models: some new evidence, Environment and Planning A 37 (2005) 525-550.

[18] R. Scarpa, M. Thiene, K. Train, Utility in WTP space: a tool to address confounding random scale effects in destination choice to the Alps, American Journal of Agricultural Economics 90 (2008) 9941010

[19] A. Daly, S. Hess, K. Train, Assuring finite moments for willingness to pay in random coefficient models, Transportation 39 (2012) 19-31. 
[20] Walker, J. L., Ben-Akiva, M. and Bolduc, D. (2007), Identification of parameters in normal error component logit-mixture (NECLM) models. J. Appl. Econ., 22: 1095-1125.Zeelenberg, M. and Pieters, R., 2007. A theory of regret regulation 1.0. Journal of Consumer Psychology, 17(1), 3-18.

[21] B. Cooper, J. Rose, L. Crase, Does anybody like water restrictions? Some observations in Australian urban communities, Australian Journal of Agricultural and Resource Economics 56 (2012) 61-81.

[22] M. Bierlaire, BIOGEME: a free package for the estimation of discrete choice models, Proceedings of the 3rd Swiss Transport Research Conference, Monte Verita, Ascona, Switzerland, 2003.

[23] M. Bierlaire, An introductory tutorial to BIOGEME Version 1.8, Monte. Verita, Ascona, Switzerland, 2009.

[24] C. Lawrence, J. Zhou, A. Tits, User's Guide for CFSQP Version 2.5: A C Code for Solving (Large Scale) Constrained Nonlinear (Minimax) Optimization Problems, Generating Iterates Satisfying All Inequality Constraints, Technical Report TR-94-16r1, Institute for Systems Research, University of Maryland, College Park, MD 20742, 1997.

[25] S. Hess, K. E. Train, J. W. Polak, On the use of a Modified Latin Hypercube Sampling (MLHS) method in the estimation of a Mixed Logit Model for vehicle choice, Transportation Research Part BMethodological 40 (2006) 147-163.

[26] W. H. Greene, D. A. Hensher, J. M. Rose, Using Classical Simulation-Based Estimators to Estimate Individual WTP Values, in: R. Scarpa, A. Alberini (Eds.), Applications of Simulation Methods in Envionmental and Resource Economics. Dordrecht, 2005, pp. 17-33.

[27] W. M. Hanemann, Welfare Evaluations in Contingent Valuation Experiments with Discrete Responses, American Journal of Agricultural Economics 66 (1984) 332-341.

[28] S. Hime, I. J. Bateman, P. Posen, M. Hutchins, A transferable water quality ladder for conveying use and ecological information within public surveys, CSERGE Working Paper (2009) EDM 01.

[29] Federal Ministry for the Environment, Nature Conservation and Nuclear Safety, Water Framework Directive. The path towards healthy waters, Berlin, 2010.

[30] S. Ferrini, R. Scarpa, Designs with a priori information for nonmarket valuation with choice experiments: A Monte Carlo study, Journal of Environmental Economics and Management 53 (2007) 342-363.

[31] Alberini, A. and Longo, A. (2009). Valuing the Cultural Monuments of Armenia: Bayesian Updating of Prior Beliefs in Contingent Valuation. Environment and Planning A, 41(2): 441-460.

[32] J. Meyerhoff, A. Dehnhardt, V. Hartje, Take your swimsuit along: the value of improving urban bathing sites in the metropolitan area of Berlin. Journal of Environmental Planning and Management 53 (2010) 107-124.

[33] Statistical Office for Berlin-Brandenburg, Data on population statistics from the regional reference system, Potsdam, 2012.

[34] Lanz, B., Provins, A., Do status quo choices reflect preferences? Evidence from a discrete choice experiment in the context of water utilities' investment planning. CEPE Working Paper (2012) No. 87.

[35] J. Meyerhoff, U. Liebe, Status Quo Effect in Choice Experiments: Empirical Evidence on Attitudes and Choice Task Complexity. Land Econ 85 (2009) 515-528.

[36] M. Schaafsma, R. Brouwer, A. Gilbert, J. v. d. Bergh, A. Wagtendonk, Estimation of DistanceDecay Functions to Account for Substitution and Spatial Heterogeneity in Stated Preference Research. Land Econ (2013) 514-537.

[37] M. Schaafsma, R. Brouwer, J. Rose, Directional heterogeneity in WTP models for environmental valuation, Ecological Economics 79 (2012) 21-31. 